\title{
Desigualdade nas exportações brasileiras de portas de madeira
}

\author{
Inequality in the brazilian exports of wooden doors
}

\author{
Maycon Thuan Saturnino da Silva1*, Gustavo Silva Oliveira1, Luciano Lambert², Nilton Novack \\ Junior'2, Philipe Ricardo Casemiro Soares ${ }^{2}$
}

\author{
${ }^{1}$ Universidade Federal do Paraná, Curitiba, PR. Brasil. *Autor para correspondência: mayconthuan@hotmail.com \\ ${ }^{2}$ Universidade do Estado de Santa Catarina, Lages, SC. Brasil.
}

\begin{abstract}
RESUMO
Neste estudo objetivou-se analisar a evolução das exportações brasileiras de portas de madeira no período de 2005 a 2015, quanto ao grau de desigualdade. Para a determinação da desigualdade utilizou-se o Índice de Gini. Para isso valores monetários das exportações foram coletados no banco de dados UNCONTRADE e deflacionados, utilizando de maneira empírica o ano base 2005. Os resultados mostraram que as exportações brasileiras de portas de madeira se caracterizaram com caráter de desigualdade muito forte a absoluta. Além disso, o valor absoluto das exportações, para o período analisado apresentou decrescimento, passando de US\$227,3 milhões em 2005 para US\$ 154,3 milhões em 2015. Desta maneira, esta análise indica que o Brasil deve expandir suas exportações, sendo de fundamental relevância a interação entre as organizações e o governo, visando elaborar e aperfeiçoar estratégias que possibilitem a competitividade do produto brasileiro frente aos demais exportadores.
\end{abstract}

PALAVRAS-CHAVE: mercado internacional, economia florestal, índice de Gini.

\begin{abstract}
The objective of this study was to analyze the evolution of Brazilian exports of wooden doors from 2005 to 2015 regarding the degree of inequality. In order to determine the inequality, the Gini Index was used. To that end, monetary values of exports were collected in the UNCONTRADE database and deflated, using empirically the base year 2005. The results showed that the Brazilian exports of wooden doors were characterized by very strong to absolute inequality. In addition, the absolute value of exports for the period analyzed increased from US \$ 227.3 million in 2005 to US \$154.3 million in 2015. In this way, this analysis indicates that Brazil should expand its exports, it is of fundamental importance the interaction between the organizations and the government, aiming at elaborating and perfecting strategies that allow the competitiveness of the Brazilian product in relation to the other exporters.
\end{abstract}

KEYWORDS: international market, forest economy, Gini index.

\section{INTRODUÇÃO}

O setor de florestas plantadas oferta cerca de $91,0 \%$ de toda a madeira com destinações industriais no país, equivalendo a uma área de efetivo plantio, em 2016, de 7,84 milhões de hectares, alcançando $\mathrm{R} \$$ 71,1 bilhões quanto ao Produto Interno Bruto (PIB) setorial (IBA 2017). Desta maneira, a relevância do segmento de portas de madeira no Brasil, está associado a produção de florestas de rápido crescimento, ocasionada pelas condições edafoclimáticas favoráveis e da biotecnologia desenvolvida, corroborando para que o país possua vantagem competitiva (DORES et al. 2016).

Neste contexto, dentre os estados brasileiros exportadores destes produtos, o estado de Santa Catarina compreendeu 75\% das exportações de portas de madeira no ano de 2015 (ACR 2016). Desta maneira, esses valores contribuem para que o estado seja de grande relevância na balança comercial de portas a nível nacional. Entretanto, a participação de outros estados no cenário das exportações de portas de madeira poderia contribuir significativamente para expansão e contribuição para economia brasileira.

Ademais, devido a contribuição do segmento de portas de madeira para o saldo da balança comercial, torna-se suma importância o estudo da disposição dos principais mercados importadores, como precursor na elaboração e implementação de estratégias que contribuam na tomada de decisões.

Conforme SOARES et al. (2014) é de grande relevância a utilização de metodologias que busquem

Rev. Ciênc. Agrovet., Lages, SC, Brasil (ISSN 2238-1171) 25 
analisar a desigualdade das exportações em todos os segmentos da economia. Deste modo, dentre as metodologias citadas na literatura o índice de Gini, é um dos principais meios de mensurar e calcular o grau da desigualdade de cada um dos países, tanto no âmbito social quanto econômico, contribuindo para que as organizações possam traçar estratégias de comércio para negociar da melhor forma seus produtos com o intuito de adquirir novos parceiros comerciais.

Neste sentido, este trabalho teve como objetivo analisar o mercado de exportação brasileira de portas, no período de 2005 a 2015, quanto a sua desigualdade.

\section{MATERIAL E MÉTODOS}

\section{Fonte de dados}

De acordo com a classificação da Nomenclatura Comum do Mercosul (NCM), portas de madeira, se enquadram no código 4418.20 (Madeira, carvão vegetal e obras de madeira - portas e respectivos caixilhos, alizares e soleiras).

Para realização deste trabalho, dados secundários disponibilizados no sistema de informação da Organização das Nações Unidas sobre o comércio de commodities - UNCOMTRADE foram utilizados. Para a determinação do índice de desigualdade, foram obtidas séries anuais do valor monetário e quantidade das exportações brasileiras no período de 2005 a 2015.

Os valores monetários de exportação foram deflacionados pelo CPI (Consumer Price Index), conforme MENDES \& PADILHA (2007), PARAPINSKI (2012), AGUIAR (2014) e VALERIUS (2016) indicada na Equação 1, tornando-se como ano base o ano de 2005.

$$
\mathrm{VR}_{\mathrm{i}}=\mathrm{VN}_{\mathrm{i}} *\left(\mathrm{CPI}_{200 \mathrm{~s}} \div \mathrm{CPI}_{\mathrm{i}}\right)
$$

Em que: $\mathrm{VR}_{\mathrm{i}}=$ Valor Real; $\mathrm{VN}_{\mathrm{i}}=$ Valor Nominal; $\mathrm{CPI}_{2005}=$ Índice para o ano base $; \mathrm{CPI}_{\mathrm{i}}=$ Índice de cada período.

\section{Medida de desigualdade}

As medidas de desigualdade são comumente empregadas para calcular a desigualdade de distribuição, além de auxiliar na interpretação dos coeficientes de concentração (HOFFMANN 2006). Deste modo, para análise da desigualdade do mercado das exportações brasileiras de portas de madeira utilizou-se o Índice de Gini, seguindo (Equação 2) adaptada por SILVA et al. (1992).

$$
\mathrm{G}=1-\sum_{\mathrm{i}=1}^{\mathrm{n}} \frac{c_{\mathrm{ij}}+c_{\mathrm{i}}}{\mathrm{n}}
$$

Em que: $\mathrm{G}$ = Índice de Gini; $\mathrm{n}$ = Número de nações; $\mathrm{C}_{\mathrm{ij}}=$ Participação acumulativa nas exportações em ordem crescente; $C_{i}=$ Participação da nação $i$.

O índice varia entre 0 e 1, sendo classificado nesta pesquisa de acordo com critérios apresentados por SILVA et al. (1992) (Tabela 1).

Tabela 1. Classificação da desigualdade pelo Índice de Gini.

Table 1. Classification of inequality by the Gini Index.

\begin{tabular}{ll}
\hline Índice de Gini & Classificação de desigualdade \\
\hline $0,101-0,250$ & nula a fraca \\
$0,251-0,500$ & fraca a média \\
$0,501-0,700$ & média a forte \\
$0,701-0,900$ & forte a muito forte \\
$0,901-1,000$ & muito forte a absoluta \\
\hline
\end{tabular}

Fonte: SILVA et al. (1992).

\section{RESULTADOS E DISCUSSÃO}

\section{Comportamento brasileiro do mercado de portas}

Buscando caracterizar o mercado brasileiro de exportação de portas de madeira, identificou-se que no período analisado, 94 países diferentes declaram importar o subproduto brasileiro, apresentando em média 86 países por ano. Dentre o período avaliado, o ano de 2014 apresentou o menor número de países (66), em contrapartida o ano de 2007 teve o número máximo (94). Desta maneira dentre os países 
identificados os principais importadores foram: Estados Unidos, Inglaterra, Canadá e França, apresentando em conjunto uma média de $80,5 \%$ das exportações brasileiras ao longo da série analisada.

Quanto aos valores absolutos, as exportações brasileiras de portas, para o período analisado, ultrapassaram os US\$227,3 milhões em 2005, entretanto apresentaram um decrescimento no ano de 2015 totalizando os US $\$ 154,3$ milhões. A Tabela 2 demonstra a oscilação das exportações de portas de madeira de 2005 a 2015.

Tabela 2. Participação percentual dos principais países importadores de portas de madeira do Brasil, durante o período de 2005 a 2015.

Table 2. Percentage share of the main importing countries of Brazilian wooden doors, during the period from 2005 to 2015.

\begin{tabular}{cccccc}
\hline Ano/País & EUA (\%) & Inglaterra (\%) & Canadá (\%) & França (\%) & Outros (\%) \\
\hline 2005 & 66,5 & 12,4 & 5,4 & 1,4 & 14,3 \\
2006 & 64,3 & 15,3 & 3,3 & 1,5 & 15,6 \\
2007 & 58,9 & 14,5 & 3,3 & 2,5 & 20,7 \\
2008 & 49,0 & 14,7 & 5,1 & 3,1 & 28,2 \\
2009 & 50,5 & 14,8 & 4,7 & 3,7 & 26,3 \\
2010 & 55,3 & 12,9 & 5,9 & 2,7 & 23,1 \\
2011 & 54,2 & 12,9 & 5,7 & 2,2 & 25,0 \\
2012 & 62,8 & 12,8 & 4,2 & 1,2 & 19,0 \\
2013 & 70,5 & 10,4 & 3,9 & 0,8 & 14,4 \\
2014 & 71,7 & 10,2 & 3,1 & 0,8 & 14,2 \\
2015 & 73,4 & 9,9 & 2,7 & 0,5 & 13,4 \\
\hline
\end{tabular}

Fonte: Elaborado pelos autores com base no UNCONTRADE 2017.

Como demostrado na Tabela 2, observa-se que durante a série analisada os Estados Unidos, apresentaram-se como o maior importador brasileiro de portas de madeira, sendo responsável por absorver sozinho cerca de $67,7 \%$ das exportações. No entanto, nota-se que a parcela das exportações destinadas a este país apresentou declínio, apresentando o menor valor no ano de 2008, fato que pode ser explicado pela crise financeira do subprime. Porém a partir do ano seguinte, as exportações já exibiram aumento significativo, e no de 2013 o país ultrapassou o percentual de importações realizadas em 2005.

Considerando as afirmações de VIEIRA (2013), verificou-se que a desaceleração do setor imobiliário norte-americano em 2006, possa explicar a diminuição das exportações para esse país, visto que em grande parte o consumo dos produtos florestais brasileiros utilizados nos Estados Unidos são destinados à construção civil. Além disso, nota-se a desvalorização do Dólar frente ao Real no ano de 2007, que associada a crise no mercado financeiro em 2008, desencadeou uma queda na importação, recuperando-se lentamente a partir de 2009.

$\mathrm{Na}$ Figura 1, verifica-se o comportamento da exportação de portas de madeira para o período de 2005 a 2015.

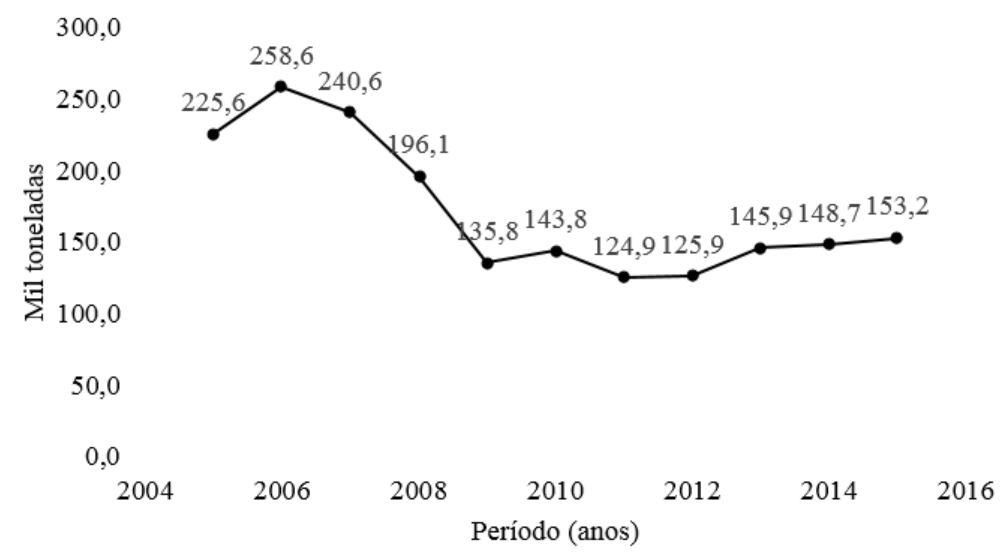

Fonte: Elaborado pelos autores com base no UNCONTRADE 2017.

Figura 1. Exportação brasileira de portas de madeira, no período de 2005 a 2015.

Figure 1. Brazilian exports of wooden doors, from 2005 to 2015. 
Na Figura 1, observa-se que as exportações apresentaram períodos de oscilações, apresentando períodos mais constantes apenas entre 2013 e 2015. Nota-se que no ano de 2006 as exportações atingiram o ápice, tendo em sequência quedas abruptas até o ano de 2009. Este cenário corrobora com as consequências desencadeadas pela crise financeira e econômica internacional. Porém, a partir de 2009, houve um período de poucas oscilações, porém mantendo-se em patamares inferiores aos verificados no início do horizonte analisado.

Dessa maneira, verifica-se que o país tem condições de retornar à realidade encontrada no ano de 2006, por meio de novos investimentos que permitam que o segmento expanda sua participação no mercado, adquirindo novos clientes.

\section{Desigualdade do mercado}

A avaliação medida pelo Índice de Gini, para o mercado de exportação de portas de madeira, apresentou de acordo com a classificação, desigualdade muito forte a absoluta em todo o período analisado (Tabela 3).

Tabela 3. Medida de desigualdade para as exportações brasileiras de portas no ano de 2005 a 2015. Table 3. Measurement of inequality for Brazilian exports of doors in the year 2005 to 2015.

\begin{tabular}{lcc}
\hline Ano & Índice de Gini & Número de países \\
\hline 2005 & 0,9537 & 88 \\
2006 & 0,9530 & 90 \\
2007 & 0,9443 & 94 \\
2008 & 0,9225 & 89 \\
2009 & 0,9207 & 83 \\
2010 & 0,9163 & 73 \\
2011 & 0,9122 & 71 \\
2012 & 0,9221 & 68 \\
2013 & 0,9363 & 67 \\
2014 & 0,9372 & 66 \\
2015 & 0,9416 & 70 \\
\hline
\end{tabular}

Fonte: Elaborado pelos autores com base no UNCOTRADE 2017.

Observa-se que houve pequenas oscilações durante o período, demonstrando que a desigualdade das exportações de portas de madeira apresentou-se estáveis. Este resultado demostra, que apenas um pequeno número de países concentra frações cada vez maiores das exportações brasileiras. $O$ ano de 2011 apresentou a menor desigualdade, seguido de 2010 e 2012, respectivamente, entretanto estas diferenças não foram significativas a ponto de classificar a desigualdade de maneira forte a muito forte.

Em relação ao número de países envolvidos, no ano de 2007 as exportações de portas de madeiras apresentaram a maior quantidade de países importadores (94 países), seguido de 2006 e 2008, respectivamente. Entretanto o ano que apresentou o maior índice de Gini foi o ano de 2005, reforçando que apesar do aumento do número de países, não houve interferência significativa nos valores de $G$.

\section{CONCLUSÃO}

Verificou-se nesse estudo que as exportações brasileiras de portas de madeira possuem um alto nível de desigualdade. Mesmo havendo muitos países importadores de portas de madeira do Brasil, apenas quatro importam grande parte do segmento. Entretanto, existem estratégias que podem ser elaboradas e implementadas, visando a expansão do mercado para demais nações. Neste sentido, recomenda-se às organizações expandir suas exportações, buscando uma maior interação com o governo para desenvolver estratégias no sentido de permitir e facilitar a competitividade do produto brasileiro de frente aos demais exportadores.

\section{REFERÊNCIAS}

AGUIAR GP. 2014. Competitividade do setor exportador brasileiro de castanha do Brasil. Dissertação (Mestrado em Ciências Florestais). Curitiba: UFPR. 140p.

ACR. 2016. ASSOCIAÇÃO CATARINENSE DE EMPRESAS FLORESTAIS. Anuário estatístico de base florestal para o estado de Santa Catarina 2016. 105p.

DORES AMB et al. 2016. Panorama setorial: setor florestal, celulose e papel. Disponível em: <http://www.bndes.gov.br/SiteBNDES/export/sites/default/bndes_pt/Galerias/Arquivos/conhecimento/liv_perspectivas 
104.pdf>. Acesso em: 05 jun. 2016.

HOFFMANN R. 2006. Estatística para economistas. São Paulo: Thomson. 432p.

IBA. 2016. INDÚSTRIA BRASILEIRA DE ÁRVORES. Relatório IBA 2016. Disponível em: <http://iba.org/images /shared/Biblioteca/IBA_RelatorioAnual2016_.pdf>. Acesso em: 20 jun. 2017.

MENDES JTG \& PADILHA JUNIOR JB. 2007. Agronegócio: uma abordagem econômica. São Paulo: Pearson Prentice Hall.

NOJIMOTO T. 1987. Obstáculos à mecanização da agricultura brasileira. Tese (Doutorado em Economia). São Paulo: USP. 345p.

PARAPINSKI ML. 2012. Desempenho das exportações brasileiras de móveis de madeira - 1991 a 2010. Dissertação (Mestrado em Ciências Florestais). Curitiba: UFPR. 151p.

SILVA JCGL et al. 1992. Estrutura de mercado do setor de papel e celulose no Brasil. In: Encontro Brasileiro de Economia e Planejamento Florestal. Anais... Curitiba. p.485-499.

SOARES PRC et al. 2014. Concentração e desigualdade nas importações norte americanas de celulose. Scientia Forestalis 42: 173-179.

UNITED NATIONS COMMODITY TRADE STATISTICS. 2016. DATABASE UNITED NATION, UNCOMTRADE: banco de dados sobre comércio internacional de mercadorias das Nações Unidas. Disponível em: <http://comtrade.un.org>. Acesso em: 25 mai. 2016.

VALERIUS J. 2016. Dinâmica do mercado mundial de molduras de madeira de coníferas e a competitividade brasileira nas importações dos Estados Unidos. Dissertação (Mestrado em Ciências Florestais). Curitiba: UFPR. 159p.

VIEIRA A. 2013. Crise Financeira e Decisões de Investimento das Empresas. Dissertação (Mestrado em Economia Monetária, Bancária e Financeira). Braga: Universidade do Minho. 75p. 